\title{
Incidence of Trichomonas vaginalis among Internally Displaced Women in Ibaka, Akwa Ibom State, Nigeria
}

\author{
E. E. Owowo ${ }^{1}$, L. E. Udofia ${ }^{2}$, S. Wisdom ${ }^{1}$, I. E. Okon ${ }^{3}$ \\ ${ }^{1}$ Department of Microbiology, Akwa Ibom State University, Ikot Akpaden, Nigeria \\ ${ }^{2}$ Department of Zoology, Akwa Ibom State University, Ikot Akpaden, Nigeria \\ ${ }^{3}$ Family Health International, Calabar, Nigeria \\ Email: etangunoowowo@aksu.edu.ng,lydiaetuk@gmail.com
}

How to cite this paper: Owowo, E.E., Udofia, L.E., Wisdom, S. and Okon, I.E. (2022) Incidence of Trichomonas vaginalis among Internally Displaced Women in Ibaka, Akwa Ibom State, Nigeria. Journal of Biosciences and Medicines, 10, 82-89. https://doi.org/10.4236/jbm.2022.103009

Received: December 26, 2021

Accepted: March 6, 2022

Published: March 9, 2022

Copyright $\odot 2022$ by author(s) and Scientific Research Publishing Inc. This work is licensed under the Creative Commons Attribution International License (CC BY 4.0).

http://creativecommons.org/licenses/by/4.0/ (c) (i) Open Access

\begin{abstract}
A total of 282 outpatient pregnant antenatal and non-pregnant women from internally displaced camps attending the Poly Health Clinic (PHC) and the Enwang Health Centre (EHC) were examined for Trichomonas vaginalis infection. Direct wet mount microscopy and Giemsa staining techniques were used on High Vaginal Swab (HVS) specimens collected on sterile swab sticks. A prevalence of 20 (57.1\%) was recorded using both methods; $12(7.2 \%)$ in PHC and 08 (6.2\%) in EHC Mbo local government area, Akwa Ibom State respectively. Differences among pregnant and non-pregnant women used were statistically significant $(\mathrm{P}<0.05)$. Women in the age group $15-19$ years had the highest prevalence of infection $03(10.5 \%)$, closely followed by those of age group 20 - 24 years 6 (6.8\%). A total number of 14 (6.7\%) infections were recorded among married women followed by single women with 06 (10\%). A higher prevalence rate of $01(24 \%)$ was recorded among women who attended Quranic level of education and 04 (16.7\%) with uneducated women, this may be due to small sample size within this group of women. 12 (6.5\%) in women with primary school education and $03(4.7 \%)$ in women with secondary school level of education. The need for improved personal hygiene in IDP camps and other effective intervention programmes among these vulnerable groups of women is advocated.
\end{abstract}

\section{Keywords}

Trichomonas vaginalis, IDPs, Ibaka

\section{Introduction}

Trichomonas vaginalis is an anaerobic, flagellated protozoan parasite and the 
causative agent of Trichomoniasis. It is the most common pathogenic protozoan infection of humans in developing countries [1]. Infection rates between men and women are similar, with women being symptomatic, while infections in men are usually asymptomatic. Transmission usually occurs via direct, skin-to-skin contact with an infected individual, most often through vaginal intercourse. The WHO has estimated that 160 million cases of infection are acquired annually worldwide [2]. The estimates for North America alone are between 5 and 8 million new infections each year, with an estimated rate of asymptomatic cases as high as $50 \%$ [3].

Most cases of $T$. vaginalis remain undiagnosed as it is currently not a target of sexually transmitted infections control and besides because of its asymptomatic nature in about half of infected men and women [4]. The disease is reported as a major cause of pathology in obstetrics and gynecology [5]. It has also been reported that the disease causes discomfort and psychosocial distress in infected patients [1]. Complications of $T$. vaginalis that have been reported among pregnant women and non-pregnant patients may include premature rupture of membranes, premature labour, low birth weight, post-abortion infections, pelvic inflammatory disease, urinary tract infection and bronchitis, pneumonia and oral lesions, and infertility [6]. Although the disease has been seen as a risk factor for other sexually transmitted agents such as Chlamydia trachomatis and Neisseria gonorrhoeae, it has also been linked to one of the predisposing factors to HIV infection, acquired immune deficiency syndrome, and cervical cancers [7].

Its symptoms are more commonly observed in women than in men. The symptoms in women may include frothy-greenish foul-smelling vaginal discharge accompanied with vulvovaginal irritation, post coital bleeding, frequency in micturition, dysuria, and lower abdominal pains [8]; preterm rupture of membranes, preterm delivery, low birth weight infants, and neonatal morbidity and mortality are symptoms associated with pregnancy [9]. Factors such as poor personal hygiene, multiple sexual partners, low socioeconomic status, and under development have been reported to be associated with high incidence of infection [10].

In Nigeria, there has been increasing prevalence of trichomoniasis in many states of the federation [11] [12], and based on the public health importance of T. vaginalis infection, The current study aimed to determine the prevalence of trichomoniasis and its associated epidemiological factors among women in internally displaced and Ibaka seaport settlements in Akwa Ibom State. Usually treatment consists of metronidazole and tinidazole [13].

\section{Aim and Objectives}

To determine the prevalence rates of Trichomonas vaginalis among women in IDP camps in Ibaka, Akwa Ibom State.

To determine the occurrence of Trichomonas vaginalis using socio-demographic 
characteristics among the participants in the IDP camps. In Ibaka Communities.

\section{Materials and Methods}

\subsection{Study Area}

This study was carried out at the Ibaka seaport settlement in Mbo Local Government Area, Akwa Ibom State, Nigeria. The Poly Health centre used is a Government health institution saddled with the responsibility of providing health-care services for the inhabitants of Ibaka and neighboring seaport settlements.

\subsection{Study Population}

A total of 282 patients and subjects were recruited for this study. The study population consisted of 200 pregnant women attending antenatal clinics and 100 non-pregnant apparently healthy subjects served as controls. The age ranged from 15 to 40 years. Informed consent was sought from the participants before specimen collection. Serial sampling was employed, and the patients who did not return their consent form were excluded from the study. The protocol for this study was approved by the Ethics and Research Committee of the Ministry of Health, Akwa Ibom State. A structured questionnaire was administered to obtain demographic characteristics (such as age, marital status, level of education and occupation) from each participant.

\subsection{Data Analysis}

Statistical analysis of the results was conducted using Chi-square at $0.05 \%$ with an appropriate degree of freedom. A P-value of a level less than $0.05(\mathrm{P} \leq 0.05)$ was considered statistically significant.

\subsection{Specimen Collection and Processing}

High vaginal swab was collected from each participant using a sterile swab stick. Briefly, exudate from the vagina was collected using a sterile swab stick aided with sterile speculum. To the exudate collected, a drop of normal saline was added and mixed. A drop of the emulsified vaginal exudate was placed on a grease-free slide and a coverslip mounted. The preparation was immediately examined microscopically using $\times 10$ and $\times 40$ objective lenses. Using its characteristic morphology and darting motility, $T$. vaginalis was identified.

\subsection{Identification of $T$, vaginalis}

Wet mounts of all swab samples were made in sterile normal saline on clean slides, covered with a cover slide and examined under the low power $(10 \times)$ and high power (40×) magnifications for presence of motile trichomonads. Pear-shaped, motile flagellates were seen moving with characteristic jerky, wobbling and rotating motions.

A smear of the secretion was also made on a slide, air-dried and fixed in absolute methanol for one minute. Diluted Giemsa stain was poured on the smear 
and allowed to stain for 10 minutes after which it was washed, air dried and examined under microscope with oil immersion $(\times 100)$ magnification for presence of trichomonads.

\section{Discussion}

The result of this study has demonstrated the prevalence and incidence of $T$. vaginalis infection in pregnant and non-pregnant women in Mbo, Akwa Ibom State. T. vaginalis was found in $13(7.2 \%)$ of the pregnant women and $07(6.9 \%)$ among non-pregnant women examined in this study (Table 1). The study shows the prevalence rate of $20(7.1 \%)$ of both pregnant and non-pregnant women in the IDP camp (Table 2). This result partly agrees with findings from previous studies, for example $4.7 \%$ reported in Illorin, Nigeria [11]; $2.7 \%$ prevalence in Jos, Nigeria [10], 2.8\% in Abakaliki, Nigeria [8] and 3.3\% in Lagos, Nigeria [14].

However, this observation is at variance with a higher prevalence rate reported in a number of other studies; for example, 12.5\% in Enugu, Nigeria [15], $15.0 \%$ in Benin City, Nigeria [16], 17.7\% in Uyo, Nigeria [17], 18.7\% in Zaria, Nigeria [18], 24.7\% in Tanzania [19], 34.0\% in Nairobi, Kenya [20] and 49.2\% in South Africa [21]. There is a general consensus that the prevalence of $T$. vaginalis varied according to settings therefore, these disparities in prevalence could be attributed to the different environmental backgrounds and hygienic condition of the subjects studied.

Amongst the different age groups investigated, $T$. vaginalis infection distribution was highest in women aged 15 - 19 years (10.5\%), followed by women aged 25 - 29 years $(7.3 \%)$ and non in women aged 40 years and above (Table 3 ). The result of this study is in agreement with generally observed fact that the incidence of sexually transmitted diseases (STDs) including trichomoniasis, by the number of cases treated each year, is highest among the 15 - 30 years age group. These age groups reported by other researchers [12] are documented to be persons with the greatest sexual activity and that incidences decrease with age.

Table 1. Incidence of $T$. vaginalis among pregnant and non-pregnant internally displaced women from Ibaka settlements.

\begin{tabular}{cccc}
\hline Subject & No. examined & No. positive & \% positive \\
\hline Pregnant & 180 & 13 & 7.2 \\
Non-Pregnant & 102 & 7 & 6.9 \\
Total & 282 & 20 & 7.1 \\
\hline
\end{tabular}

Table 2. Prevalence of trichomonas infection among internally displaced women from Ibaka settlements.

\begin{tabular}{cccc}
\hline Health Facility & No. examined & No. infected & \% Infected \\
\hline Poly Clinic Ibaka & 159 & 12 & 7.2 \\
Enwang Health Centre & 123 & 8 & 6.5 \\
Total & 282 & 20 & 7.1 \\
\hline
\end{tabular}


Table 3. Age-specific distribution of infection among internally displaced pregnant and Non-pregnant women from Ibaka settlements.

\begin{tabular}{cccc}
\hline Age $(\mathrm{yrs})$ & No. tested & No. infected & \% positive \\
\hline $15-19$ & 38 & 3 & 10.5 \\
$20-24$ & 88 & 6 & 6.8 \\
$25-29$ & 110 & 9 & 7.3 \\
$30-34$ & 24 & 1 & 4.2 \\
$35-39$ & 20 & 1 & 5 \\
$40-44$ & 2 & 0 & 0 \\
Total & 282 & 20 & 7.1 \\
\hline
\end{tabular}

Women with pregnancy were observed to be more infected with $T$. vaginalis (7.2\%), followed by non-pregnant women with (6.9\%). Information retrieved from pregnant women revealed that the frequency of sexual intercourse during pregnancy decreases as number of children increases and this may likely be the reason for the low incidence of infection among advance marriages (Table 1). Our finding is consistent with previous report in Imo state, Nigeria [11] who reported that young marriages had the highest prevalence of STDs.

However, this observation was in contrast with findings in Abakaliki, Nigeria who reported that advance marriages were more infected with $T$. vaginalis in their study. Marital status of pregnant women examined for $T$. vaginalis in this study was also found to be significantly associated with infection acquisition ( $\mathrm{P}$ $<0.05$ ). Single (unmarried) pregnant women were found to be more infected (10\%) than the married (6.7\%) (Table 4). This pre-supposes that unmarried women are unattached thus free to indulge in more sexual activities probably involving multiple sexual partners. This corroborates findings by Okpara et al. [10] who reported that single women were more infected in their study. In a related study a statistically significant association was found between trichomoniasis, prostitution, no condom use and other STDs [10].

Occurrence of $T$. vaginalis infection by level of education revealed that, illiterate women (16.7\%) and (24\%) women with Quranic education had the highest infection with $T$. vaginalis recorded in this study (Table 5), followed by women with the primary school leaving certificate categories with (6.5\%) and secondary school certificate holders (4.7\%). This was clearly due to the extremely small number of women in those groups examined as shown in Table 5. Thus, there was significant association between educational status and infection occurrence $(\mathrm{P}>0.05)$, an observation that is in agreement with several studies [8] that have significantly linked educational status with infection occurrence.

The use of wet mount and Giemsa staining methods greatly enhanced the detection of $T$. vaginalis trophozoites that would have been missed by direct wet mount technique alone. Despite the limited sensitivity of these methods, direct wet microscopic examination of vaginal swab specimens alone remain the most 
Table 4. Occurrence of infection by marital status of the pregnant and non-pregnant women in internally displaced camp from Ibaka.

\begin{tabular}{cccc}
\hline Marital & No. & No. & $\%$ \\
\hline Status & tested & positive & positive \\
Single & 60 & 6 & 10 \\
Married & 210 & 14 & 6.7 \\
Divorced/septed & 8 & 0 & 0 \\
Widow & 4 & 0 & 0 \\
Total & 282 & 20 & 7.1 \\
\hline
\end{tabular}

Table 5. Occurrence of infection according to the educational status of pregnant and non-pregnant women in IDP camp, Ibaka.

\begin{tabular}{ccc}
\hline Education & No. Tested & No (\%) Positive \\
\hline None & 24 & $04(16.7)$ \\
Quranic & 04 & $01(24.0)$ \\
Primary & 186 & $12(6.50)$ \\
Secondary & 64 & $03(4.70)$ \\
Tertiary & 04 & $00(0.00)$ \\
Total & 282 & $20(7.10)$ \\
\hline
\end{tabular}

Key: No: Number.

widely utilized diagnostic test for the infection in most hospitals and this is reported to have a sensitivity of only about $60 \%-80 \%$ [18]. According to some researchers [14], culture method is considered to be far superior to wet mount examination for the detection of the organisms and is currently the gold standard which should be considered for widespread clinical use.

The high incidence of $T$. vaginalis infection worldwide, co-infection with other sexually transmitted infections and attendant high risk of pelvic inflammatory diseases and tubal infertility make trichomoniasis a compelling public health concern [22].

Certain factors such as poor personal hygiene, multiple sex partners, and low socio-economic status with under development are also associated with high incidence of infection [23]. Neonatal trichomoniasis can be acquired during passage through an infected birth canal and it is estimated that $2 \%-17 \%$ of female babies acquire trichomoniasis through direct vulvo-vaginal contamination. Trichomoniasis is an infection of multiple sites (e.g. vaginal epithelium, skene glands, bartholin glands and urethra), thus prompt diagnosis is important for eliminating infection in the patient and sexual partners and treatment of sexual partners is thought to increase cure rates [24].

\section{Conclusion}

Our study has confirmed the endemicity of Trichomonas vaginalis infection 
among pregnant women in Ibaka, Mbo local government of Akwa Ibom State and suggests that the control of trichomoniasis can best be accomplished by public health programmes through persistent efforts to educate people on the need to improve on their personal hygiene, screen, diagnose, treat patients and sexual partners and follow up on the high risk individuals within communities.

\section{Conflicts of Interest}

The authors declare no conflicts of interest regarding the publication of this paper.

\section{References}

[1] Schwebke, J.R. (2002) Update of Trichomoniasis. Sexually Transmitted Infection, 78, 378-379. https://doi.org/10.1136/sti.78.5.378

[2] Harp, D.F. and Chowdhury, I. (2011) Trichomoniasis: Evaluation to Execution. European Journal of Obstetrics \& Gynecology and Reproductive Biology, 157, 3-9. https://doi.org/10.1016/j.ejogrb.2011.02.024

[3] Swygard, H., Sena, A.C. and Hobbs, M.M. (2004) Trichomoniasis: Clinical Manifestations, Diagnosis and Management. Sexually Transmitted Infections, 80, 91-95. https://doi.org/10.1136/sti.2003.005124

[4] Sobel, J.D. (2005) What's New in Bacterial Vaginosis and Trichomoniasis? Infectious Disease Clinics of North America, 19, 387-406. https://doi.org/10.1016/j.idc.2005.03.001

[5] Huppert, J.S. (2009) Trichomoniasis in Teens: An Update. Current Opinion in Obstetrics \& Gynecology, 21, 371-378.

https://doi.org/10.1097/GCO.0b013e32832e0827

[6] Smith, D.A. and Ramos, N. (2010) Trichomoniasis. eMedicine.

[7] Crosby, R., Di-Clemente, R.J., Wingwood, G.M., Harrington, K., Davies, S.L., Hook, 3rd, E.W., et al (2002) Predictions of Infection with Trichomonas vaginalis: A Prospective Study of Low-Income African-American Adolescent Females. Sexually Transmitted Infections, 78, 360-364. https://doi.org/10.1136/sti.78.5.360

[8] Uneke, C.J., Cletus, D.C., Ugwuoru, E.A. and Mirian, A. (2006) Trichomonas vaginalis Infection among Pregnant Women in South-Eastern Nigeria: Public Health Significance. The Internet Journal of Gynaecology and Obstetrics, 6, 1528-1540.

[9] Bowden, F.J. and Garnett, G.P. (2000) Trichomonas vaginalis Epidemiology: Parameterizing and Analyzing a Model of Treatment Interventions. Sexually Transmitted Infections, 76, 248-256. https://doi.org/10.1136/sti.76.4.248

[10] Okpara, K., Udoidung, N., Ating, I., Bassey, E., Okon, O and Nwabueze, A. (2009) Risk Factors for Vaginal Trichomoniasis Among Women in Uyo, Nigeria. The Internet Journal of Health, 9, 1-5.

[11] Nwosu, M.N., Mba, I.E.K., Opara, C. and Nwajuaku, C. (2001) Genital Ulcers and Sexual Transmitted Disease in Rural Nigeria. Journal of Medical Investigation and Practice, 2, 28-33.

[12] Usanga, V.U., Abia-Bassey, L., Inyang-Etoh, P.C. and Udoh, S. (2010) Trichomonas vaginalis Infection among Pregnant Women in Calabar, Cross River State, Nigeria. The Internet Journal of Gynecology and Obstetrics, 14, 101-107.

[13] World Health Organization (WHO) (2007) Sexually Transmitted Infection. WHO Media Center. 
[14] Obiajuru, I.O.C. and Ogbulie, J.N. (2005) Comparative Study of the Prevalence of Sexually Transmitted Diseases between Pregnant Women and Non-Pregnant Women in Imo state, Nigeria. Global Journal of Pure and Applied Sciences, 3, 339-342.

[15] Onyido, A.E., Umeanaeto, P.U., Irikannu, K.C., Ekwunife, C.A., Ezeanya, L.C., Nwangwu, U.C., Ugha, C.N. and Obiechina, I.O. (2014) Prevalence of Trichomons vaginalis among the Rural Women of Ekwulumili Community Anambra State, Southeastern, Nigeria. Journal of Natural Science, 12, 129-134.

[16] Ochei, K.C., Obeagu, E.I., Ugwu, G.U. and George, C.N. (2014) Prevalence of Trichomonas vaginalis among Pregnant Women Attending Hospital in Irrua Specialist Teaching Hospital in Edo State, Nigeria. IOSR Journal of Dental and Medical Sciences, 13, 79-82.

[17] Agboola, A. (2006) Vaginal Discharge. In: Agboola, A., Ed., Textbook of Obstetrics and Gynecology for Medical Students, 2nd Edition, Heinemann Educational Books, Ibadan, 70-72.

[18] Jatau, E.D., Olonitola, S.A. and Olayinka, A.T. (2006) Prevalence of Trichomonas Infection among Women Attending Antenatal Clinics in Zaria, Nigeria. Annals of African Medicine, 5, 178-181.

[19] Caini, S., Gandini, S., Dudas, M., Bremer, V., Severi, E. and Gherasim, A. (2014) Sexually Transmitted Infections and Prostate Cancer Risk: A Systematic Review and Meta-Analysis. Cancer Epidemiology, 38, 329-338. https://doi.org/10.1016/j.canep.2014.06.002

[20] Segundo, R.L., Kelika, A.K., Kyle, T.B., Jose, B.P., Ana, M.R. and Carlos, F.C. (2009) Trichomonas vaginalis Infection and Associated Risk Factors in a Socially-Marginalized Female Population in Coastal Peru. Infectious Diseases in Obstetrics and Gynecology, 2009, Article ID: 752437. https://doi.org/10.1155/2009/752437

[21] Cudmore, S.L., Delgaty, K.L., Hayward-Mcclelland, S.F., Petrin, D.P. and Garber, G.E. (2004) Treatment of Infections Caused by Metronidazole-Resistant Trichomonas vaginalis. Clinical Microbiology Reviews, 17, 783-93. https://doi.org/10.1128/CMR.17.4.783-793.2004

[22] Johnston, V.J. and Mabey, D.C. (2008, February) Global Epidemiology and Control of Trichomonas vaginalis. Current Opinion in Infectious Diseases, 21, 56-64. https://doi.org/10.1097/QCO.0b013e3282f3d999

[23] Jombo, G.T.A., Egah, D.Z., Banwate, E.B. and Opajobi, S.O. (2006) High Vaginal and Endocervical Swabs: A Bacteriological Study of 8,433 Samples in Jos, Nigeria. Journal of Medical Laboratory Science, 15, 41-46.

[24] Garber, G.E. (2005, January) The Laboratory Diagnosis of Trichomonas vaginalis. Canada Journal Infectious Disease Medical Microbiology, 16, Article ID: 373920. https://doi.org/10.1155/2005/373920 